\title{
Do LGBT-supportive Corporate Policies Enhance Firm Performance?
}

\begin{tabular}{c} 
Shaun Pichler \\
California State University, Fullerton \\
800 N. State College Boulevard \\
Fullerton, CA 92831 \\
(657) 278-7373 \\
spichler@fullerton.edu \\
Janell L. Blazovich \\
University of St. Thomas \\
2115 Summit Avenue \\
St. Paul, MN 55101 \\
(651) 962-5434 \\
jblazovich@stthomas.edu \\
Kirsten A. Cook \\
Texas Tech University \\
Lub Flint Avenue, P.O. Box 42101 \\
Lubbock, TX 79409 \\
(806) 834-7737 \\
kirsten.cook@ttu.edu \\
Janet M. Huston \\
Arizona State University \\
P.O. Box 873606 \\
Tempe, AZ 85287 \\
(480) 727-9575 \\
janet.huston@asu.edu \\
William R. Strawser \\
william.strawser@ucdenver.edu \\
Denver, Colorado Denver 80202 \\
\hline
\end{tabular}

This is the author manuscript accepted for publication and has undergone full peer review but has not been through the copyediting, typesetting, pagination and proofreading process, which may lead to differences between this version and the Version of Record. Please cite this article as doi: $10.1002 / \mathrm{hrm} .21833$

This article is protected by copyright. All rights reserved. 
Author bios:

Shaun Pichler:

Dr. Shaun Pichler (Ph.D., Michigan State University) is an Associate Professor of Management at the Mihaylo College of Business \& Economics at California State University, Fullerton where he teaches courses in human resource management and organizational behavior. Shaun has published in journals such as Human Resource Management, Journal of Occupational \& Organizational Psychology, Journal of Vocational Behavior, and Personnel Psychology, among others. He is a current editorial board member for Academy of Management Review, Equality, Diversity \& Inclusion: An International Journal, Human Resource Management, Journal of Occupational \& Organizational Psychology, and Journal of Vocational Behavior.

Janell Blazovich:

Janell Blazovich is an Associate Professor of Accounting in the Opus College of Business at the University of St. Thomas. She holds a Bachelor of Business Administration degree from Marquette University, a Master of Business Taxation degree from the University of Minnesota, and a Ph.D. in Accounting from Texas A\&M University.

\section{Kirsten Cook:}

Kirsten Cook is an Associate Professor of Accounting in the Rawls College of Business at Texas Tech University. He holds an Associate in Arts degree from McLennan Community College, Bachelor of Business Administration and Master of Accountancy degrees from Baylor University, and a Ph.D. in Accounting from Texas A\&M University.

Janet Huston:

Janet McDonald Huston is a Clinical Assistant Professor of Accounting at Arizona State University. She received her Ph.D. from Texas A\&M University. Her research interests are in the areas of financial reporting and taxation. Her research appears in Issues in Accounting Education and Business Horizons.

William Strawser:

William Strawser is an Assistant Professor at the University of Colorado Denver Business School. He obtained his Bachelor of Arts in Economics from the University of Texas at Austin and his Master of Science in Accounting and Ph.D. in Accounting from Texas A\&M University. 
[rh] Work-life support practices and customer satisfaction

\title{
Work-Life Support Practices and Customer Satisfaction: The Role Of TMT Composition and Country Culture
}

\author{
(lnos \\ Julie A. Cogin, Karin Sanders, and Ian O. Williamson
}

\begin{abstract}
Despite the growing prevalence of work-life support (WLS) practices in companies, there is a lack of theoretical and empirical clarity on their benefits to organizational performance. It is also unclear if the organizational performance effects of WLS practices vary based on an organization's internal and external environments. The dual objective of this paper is to investigate whether WLS practices relate to customer-focused outcomes and if so, under which conditions WLS practices yield benefits. Drawing on contingency theory we examine how the boundary conditions of internal firm characteristics (e.g., percentage of top management team (TMT) members with children) and external environmental factors (e.g., gender egalitarianism of the country) moderate the relationship between WLS practices and customer satisfaction. We shed light on these issues by examining multi-source, longitudinal data collected over three years from a multinational corporation operating in 27 countries. The results show that both percentage of TMT members with children and gender egalitarianism of the country strengthen the relationship between WLS practices and customer satisfaction. The findings provide insights into the circumstances when WLS practices provide performance benefits for firms and the translatability of these benefits from one country to another.
\end{abstract}

Keywords: Human Resource Management, work-family, customer satisfaction, upper echelon perspective, gender egalitarianism

Correspondence to: Julie A. Cogin, Professor, Australian Graduate School of Management, University of New South Wales, UNSW Sydney, NSW 2052. Australia, Ph: 61293859719 Email: Julie.cogin@agsm.edu.au.

\section{Introduction}

The past two decades have seen dramatic shifts in the composition of the global workforce. Over this time, a greater number of women with children have joined the workforce, the proportion of dual-career couples has increased, single-parent households have risen and an ageing population has resulted in growing numbers of employees with elder care responsibilities (Butts, Casper \& Yang, 2012; Wood \& de Menezes, 2010). Along with these demographic shifts, employees are experiencing increased work-life conflict as they struggle to balance their work and non-work commitments (Allen, Herst, Bruck \& Sutton, 2000). In response to these trends a 
growing number of organizations have invested in work-life support (WLS) practices that provide employees with flexibility to help them to manage their various responsibilities (Piszczek \& Berg, 2015; Kailasapathy, Kraimer \& Metz, 2014). While the attributes of WLS initiatives differ across firms, WLS practices often include flexible work schedules, teleworking, job sharing, working from home, leave of absence or gap leave and dependent care programs (Butts et al., 2012).

Given the increased availability of WLS practices, a growing body of research has examined the outcomes associated with these practices. To date, the majority of this research has examined the influence of WLS practices on employee outcomes. In general, these results show that WLS practices can generate positive job attitudes, increased organizational commitment and reduced employee turnover intentions (see meta-analyses by Butts et al., 2012; and Kossek, Pichler, Bodner \& Hammer, 2011, and a review article by Kelly, Kossek, Hammer, Durham, Bray et al., 2008). Research investigating the effects of WLS practices on individual outcomes has examined different boundary conditions, such as family-friendly organization perceptions, work-to-family conflict (Butts et al., 2013); supervisor characteristics (Hammer, Kossek, Bodner \& Crain, 2013) and attitudes of employees' spouse/partners (Wayne, Casper, Matthews \& Allen, 2013). Analyses of these boundaries conditions provide an understanding of what companies need to put in place, or consider in order to maximize the individual outcomes resulting from WLS practices.

While there is growing evidence that WLS practices can influence positive employee outcomes, only a small body of work has examined how WLS practices impact firm outcomes (Kelly et al., 2008). Conceptually, the resource-based view predicts that firm-specific investments in the development and implementation of Human Resource Management (HRM) practices, such as WLS practices, can impact firm performance by shaping the collective and shared behaviors of 
a firm's workforce (Fulmer \& Ployhart, 2014). By influencing how employees use their skills, judgment, knowledge and relationships, WLS practices have the potential to enhance a firm's ability to execute critical activities that can create value for their customers and are hard for competitors to imitate (Barney, 1991). Consistent with this logic, studies have found a positive link between WLS practices and firm outcomes, such as shareholder returns (Arthur, 2003), share price (Arthur \& Cook, 2004), market- and human resource-related performance (Ngo, Foley \& Loi, 2009; Wood \& De Menezes, 2010), productivity (Konrad \& Mangel, 2000) and perceived firm financial performance (Perry-Smith \& Blum, 2000).

Scholars have nevertheless noted limitations in research on the relationship between WLS and firm performance and have identified at least two potential approaches to addressing these limitations. First, researchers have called for a clearer conceptual and empirical understanding of whether WLS practices impact a wider range of firm performance outcomes, such as nonfinancial firm outcomes (Kelly et al., 2008). While there is growing acceptance among practitioners and scholars that HRM practices can impact both firm financial (e.g., revenue, profit, and market performance) and non-financial outcomes (e.g., customer satisfaction, product quality and innovation), there is also recognition within the HRM literature that the nature of the relationship between a human resource (HR) practice and a specific type of performance outcome can be unique to that outcome (e.g., Fulmer \& Ployhart, 2014). Thus, while there is evidence that WLS practices influence financial and productivity-related outcomes (e.g., Arthur, 2003; Arthur \& Cook, 2004; Konrad \& Mangel, 2000; Ngo et al., 2009; Perry-Smith \& Blum, 2000; Wood \& De Menezes, 2010), there is a need to extend research to examine how WLS practices influence firm non-financial outcomes in order to gain a more complete understanding of the performance implications of these practices. 
Second, in the same way that individual-level research has examined the boundary conditions that maximize the value created by WLS practices on employees, research at the organizational level should seek to illuminate the optimal boundary conditions for WLS practices to contribute to firm performance. However, to date research examining the boundary conditions of the relationship between WLS practices and organizational outcomes is limited. Contingency theory predicts that the performance benefits associated with investments in HR practices may vary based upon situational characteristics and the context in which they are applied (Colakoglu, Allen, Miah \& Bird, 2016; Boxall \& Purcell, 2011; Wright \& Snell, 1998). These characteristics can include both internal firm attributes (e.g., strategy, leadership, workforce features) and attributes of a firm's external environment (e.g., economic conditions, social norms and culture, competition) (see Li, Qin, Jiang, Zhang \& Gao, 2015 and Schuler, Dowling \& De Cieri's, 1993). Building upon this research, we seek to provide greater clarity about whether WLS practices generate firm-level benefits and if internal and external boundary conditions influence when this relationship occurs.

Our study extends the present literature in several ways. We examine how WLS practices impact firm non-financial performance outcomes, namely customer satisfaction. Customer satisfaction is defined as a customer's overall evaluation of the performance of a product or service (Johnson \& Fornell, 1991). We focus on customer satisfaction because of the potential value it offers businesses. From a strategic perspective, customer satisfaction is a critical aspect of a firm's strategic performance framework (O'Connell \& O'Sullivan, 2013) with consistent and compelling evidence showing that customer satisfaction can serve as a reliable indicator of an organization's future financial performance (e.g., Nagar \& Rajan, 2005). For example, research has demonstrated that for a typical company a relatively small increase in customer satisfaction can generate substantial increases in firm return on investment, market value of equity (above and 
beyond the accounting book values of assets and liabilities), net operating cash flow, and a reduction of variance in future cash flows (Anderson, Fornell \& Mazvancheryl, 2004; Gruca \& Rego, 2005). Further, from a service marketing perspective, customer satisfaction has been shown to be a central determinant of repeat business (Guo, Xiao \& Tang, 2009), a strong predictor of customer loyalty intentions across a wide range of product and service categories (Gustafsson, Johnson \& Roos, 2005) and a usefulness measure of performance to both manufacturing and service organizations (Liao \& Subramony, 2008). The HRM literature indicates that customer experiences are influenced by the attitudes and behaviors of employees (e.g., Batt, 2002; Nishii, Lepak \& Schneider, 2008). Thus, given that a firm's WLS practices can impact employees' attitudes and behaviors, we propose the availability of WLS practices can have a positive impact on firm customer satisfaction.

Nonetheless availability of WLS practices alone does not necessarily mean they will be equally utilized and impact firm customer satisfaction outcomes. Drawing upon contingency theory, we also extend existing research by investigating how internal firm and external environmental factors influence the relationship between WLS practices and customer satisfaction. Regarding internal firm attributes, we examine the characteristics of the organization's top management team (TMT). While organizations may invest in WLS practices, for any performance benefits to be realized, it is crucial that employees feel supported by management to make use of the WLS initiatives on offer (Valcour, Ollier-Malaterre, Matz-Costa, Pitt-Catsouphes, et al., 2011). Upper echelon theory predicts that the demographic characteristics of an organization's TMT influences managers' perceptions, preferences and expectations of why and how different initiatives can be utilized within the organization (Hambrick \& Mason, 1984; Nielsen \& Nielsen, 2011). Thus, TMT attributes may play an important role in shaping how WLS initiatives are utilized in firms and, as a result, the benefits they create for firms. While supportive 
workplaces have been shown to play a significant role in reducing employees' work-family stress (Greenhaus, Ziegert \& Allen, 2012), little attention has been devoted to the context in which the support is created and no research has examined how attributes of the TMT enhance or constrain the benefits firms derive from WLS practices. One attribute of the TMT that we identify as particularly relevant in the context of our study is the percentage of TMT members with children. We theorize that TMT members with children will be sensitive to the challenges of balancing work and non-work responsibilities and therefore will be more supportive of employees making use of available WLS initiatives, thereby leading to greater performance benefits.

With regard to external factors, we examine the national culture of an organization's environment because of growing sentiment that the effect of HRM practices may vary across countries that have different cultures (Stavrou \& Kassinis, 2013; Rabl, Jayasinghe, Gerhart \& Kuhlmann, 2014). National culture may be of particular importance when considering the performance implications of WLS practices because culture shapes beliefs about what constitutes appropriate work and non-work activities (Ollier-Malaterre, Valcour, Dulk \& Kossek, 2013). One cultural value that has been identified as particularly relevant to how members of a society conceptualize work and non-work roles is the country's gender egalitarianism values and practices (Lyness \& Judiesch, 2014). Gender egalitarianism is defined as the extent to which a society believes in gender equality, such that high gender egalitarianism is associated with the belief that men and women should receive equal treatment (House, Javidan, Hanges \& Dorfman, 2002). In high gender egalitarian settings, it is socially acceptable for work and family responsibilities to be shared across women and men. Thus, we theorize that work and non-work conflict may be more relevant to employees in high gender egalitarian cultures due to more employees having dual responsibilities (Ruppanner \& Huffman, 2014). As such, we predict that 
WLS practices will be more valued by employees in high gender egalitarian settings, resulting in WLS practices yielding superior customer satisfaction benefits in these settings.

By responding to calls to adopt more robust research designs (Peterson, Arregle \& Martin, 2012; Bainbridge, Sanders, Cogin \& Lin, 2016), in this study we examine the relationship between WLS practices and customer satisfaction by using multi-source, longitudinal data collected over three years. Our focal context is subsidiaries of a European multinational corporation (MNC) operating in 27 countries. Examining the impact of WLS practices on firm outcomes in an MNC context is important because the largest $500 \mathrm{MNCs}$ control over half of global world trade (World Trade Organization, 2013) and, according to Batt, Holman and Holtgrewe (2009: 474), this "disproportionately influences the direction of change" in how people are managed around the globe. Examining the impact of WLS practices in a multinational setting thus provides an excellent venue to examine the relationship between WLS practices and customer satisfaction and how internal and external factors influence this relationship.

\section{Theory and Hypotheses}

\section{The relationship between WLS practices and customer satisfaction}

In the current global marketplace, where organizations face growing competition, customer satisfaction is a key driver of organizational success (Kumar \& Petersen, 2005). While many factors can shape customer satisfaction (e.g., product quality, price, product attributes), one key aspect is the quality of service customers receive from the employees of an organization (Schneider, White \& Paul, 1998). Logically, the attitudes and behaviors of front-line employees that interact with customers on a daily basis play an important role in shaping customers' satisfaction. Non-customer-facing staff (e.g., back-office staff and management) also play an important role in affecting customer experiences by providing assistance to those directly 
interacting with customers. This may include providing timely and accurate information and revising internal processes to meet customer demands. Thus, customer satisfaction is ultimately influenced by the collective attitudes and behaviors of an entire workforce as opposed to just those employees who interact directly with customers (Schneider et al., 1998; see also Lin, Sanders, Sun, Shipton, \& Mooi, 2016).

Customer satisfaction is closely linked to the willingness of employees to go beyond the confines of their job description to satisfy customer requests (Nishii et al., 2008). Satisfying customers' unique needs often means that employees cannot rely upon standard scripts or procedures, but must exert effort to develop new approaches to meet customer demands (Morrison, 1996). This type of discretionary behavior can generate significant rewards for firms in the form of more satisfied customers that are likely to engage in repeat business and increased purchases (Beltrán-Martín, Roca-Puig, Escrig-Tena \& Carlos, 2008). Employees’ willingness to exert discretionary effort is essential to high customer satisfaction (Rucci, Kirn \& Quinn, 1998).

Social exchange theory suggests that positive actions for the benefit of employees are perceived by employees as an indication that the organization cares about them (Eisenberger, Stinglhamber, Vandenberghe, Sucharski \& Rhoades, 2002). Supportive formal or informal organizational practices can create a feeling of obligation among employees to reciprocate by exhibiting behaviors that are beneficial to the organization, such as high levels of discretionary effort (Aryee, Budhwar \& Chen, 2002; Cropanzano \& Mitchell, 2005). Based on this logic we argue that WLS practices can enhance customer satisfaction by motivating employees to engage in the discretionary behavior needed to exceed customer expectations.

An inability to balance work and non-work responsibilities can produce negative outcomes for employees, such as job dissatisfaction, job burnout, turnover, depression, and life and marital dissatisfaction (Allen et al., 2000). Engaging in WLS practices sends a strong signal 
to the workforce that the organization is supportive of their well-being (Grover \& Crooker, 1995). This in turn can foster a feeling of reciprocity among the workforce that translates into high levels of discretionary effort needed for superior customer satisfaction. Indeed, employee perceptions that their employer supports work-life integration have been found to be a powerful tool for fostering and sustaining employee engagement and productivity (Valcour et al., 2011). Furthermore, Lambert (2000:801) found that work-family practices prompted employees to show greater initiative as "workers may feel obligated to exert extra effort in return for extra benefits." Therefore, we formulate our first hypothesis as follows:

Hypothesis 1: The availability of WLS practices has a positive effect on a subsidiary's customer satisfaction.

\section{Contextual factors influencing the relationship between WLS practices and customer satisfaction}

A key premise underlining our first hypothesis is that availability of WLS practices will be received positively by employees, motivating them to engage in discretionary effort that supports high levels of customer satisfaction. Implicit in this logic is the idea that all firms: (i) will be equally capable of creating an internal environment that complements implementation of WLS practices; and (ii) that workforces across all firms will find WLS practices equally attractive. However, it is likely that these two assumptions may not always hold true. For example, even when WLS practices are available, managers of a firm may not create an environment that encourages employees to make use of them (Kossek et al., 2011). Furthermore, issues of work and non-work conflict may be more or less salient in certain cultures, potentially impacting the relevance of WLS practices to workforces from different countries (Aryee, Srinivas \& Tan, 2005; Kinnunen \& Mauno, 1998). 
Contingency theory asserts that the effectiveness of an HR practice will be affected by the context within which it is adopted (Wright \& Snell, 1998; Boxall \& Purcell, 2011). Building upon contingency theory Schuler and colleagues (1993) offer an integrative framework for the study of HRM in an MNC setting. The framework emphasizes the need to consider internal and external factors when examining the impact of HR practices in MNCs. Using this framework we posit that consideration of internal and external attributes provides a richer understanding of how WLS practices influence customer satisfaction. In the case of internal attributes, we focus on the attributes of a firm's TMT because of the important role this group plays in shaping how formal HR policies are interpreted and experienced in organizations. In regard to external attributes we examine the role of country culture because of the function culture plays in shaping employees' norms and beliefs about work and non-work roles, which can influence how employees perceive the value of WLS practices.

Attributes of a firm's TMT. The upper echelon perspective theorizes that a firm's ability to derive value from its management practices is influenced by the characteristics of a firm's leadership team. As Hambrick (1989:5) noted: "If we want to explain why organizations do the things they do, or, in turn, why they perform the way they do, we must examine the people at the top." The collective attributes (e.g., experiences, values and backgrounds) of the TMT influence how team members frame strategic problems and what actions they perceive are available to the firm to solve these problems (Hambrick \& Mason, 1984). As a result, TMTs with different characteristics may be better or worse at implementing firms' HR practices, which in turn can have a cascading effect on organizational outcomes (Chadwick, Super, \& Kwon, 2015; Hambrick \& Mason, 1984; Finkelstein \& Hambrick, 1996). Consistent with this logic, several studies have found an association between TMT characteristics and firm-level outcomes (e.g., Barker \& Mueller, 2002; Higgins \& Gulati, 2006, Somaya, Williamson \& Zhang, 2007). 
Drawing upon the upper echelon perspective, we expect that attributes of TMT members will influence their perception of the usefulness of WLS practices. Specifically, we argue that when the proportion of TMT members with children is high, members of the TMT will be more sensitive to the challenges of balancing work and non-work responsibilities based on their current and/or past experiences as parents raising children. Given their awareness of the challenges associated with balancing work and non-work obligations, we propose that TMTs with a high proportion of members with children will be more likely to create a culture where employees feel supported and comfortable to utilize WLS practices, which in turn will increase employees' motivation to exert the discretionary effort needed to meet customers' unique needs and requirements. Thus, we formulate our second hypothesis as follows:

Hypothesis 2: The positive relationship between WLS practices and customer satisfaction is moderated by the proportion of TMT members with children, such that a high proportion of TMT members with children will strengthen the relationship between WLS practices and customer satisfaction.

Country culture. Most of the key concepts studied in the work-life literature are rooted in cultural assumptions about what are appropriate work and non-work activities (Powell, Francesco \& Ling, 2009). For example, extant models of the work-life interface have primarily been developed in Western countries that uphold the idea that both women and men should have fulfilling lives at work and at home (Hofstede, 2001; Yang, Chen, Choi \& Zou, 2000). This underlying assumption is a primary justification for organizations to implement WLS practices that help employees balance and fulfil their work and non-work responsibilities. However, when Western managerial practices are disseminated across borders and embedded in different cultural contexts, they may not always fit the environment of the recipient country, which, in turn, may reduce the effectiveness of those practices in that country (Colakoglu, Allen, Miah \& Bird, 2016). A reason for a reduced effect is the great variation in the values held by different societies about 
work (Stavrou, Casper \& Ierodiakonou, 2015). This means that the value of WLS practices to firm performance may vary depending on the cultural values regarding work that exist in the country where a company operates (Stavrou \& Kassinis, 2013).

One cultural value that has been identified as particularly relevant to how members of society conceptualize work and non-work roles is gender egalitarianism. In cultures with low gender egalitarianism, men are regarded as being responsible for providing the financial support for a family and women's roles are associated with family caregiving (Cotter, Hermsen \& Vanneman, 2011). In cultures with high gender egalitarianism, there is less adherence to the traditional division of work and non-work activities by gender (Cotter et al., 2011). Aryee and colleagues (2005) undertook a study of work-family balance in India, a low gender egalitarianism country, and confirmed that men had significantly higher levels of job involvement than women, with the opposite being true for family involvement. In Finland, a high gender egalitarian society, men and women were found to experience many aspects of work and non-work responsibilities similarly (Kinnunen \& Mauno, 1998). Thus, there is prior evidence that differences across countries on gender egalitarianism are related to differences in women's and men's work and non-work roles.

We expect that in countries with high gender egalitarianism, the effect of WLS practices will be stronger because of the sharing of work and non-work roles across men and women. In this context, men and women may be more likely to experience conflict between work and nonwork responsibilities because of time constraints. For example, in their study of employees across 31 countries Ruppanner and Huffman (2014) found that men and women in countries with high (compared to low) gender empowerment reported higher levels of work and non-work interference. As such, the availability of WLS practices may be perceived as more useful by 
employees in high gender egalitarianism societies, resulting in WLS being more effective in driving the discretionary effort needed for high customer satisfaction in these setting.

Conversely, in low gender egalitarian countries men will be expected to focus on their work responsibilities in order to fulfil the cultural expectation that they provide for their families' financial needs, while women will be expected to take on family caregiving roles and place low emphasis on work responsibilities. This value structure will make WLS practices less relevant because of a lower perceived need by men and women to balance work and non-work responsibilities. This however does not mean that women or men in low egalitarian countries will not utilize or appreciate WLS practices, but that this will be less in comparison to women and men in high egalitarian countries. As a result, WLS practices are likely to be less effective in driving the discretionary effort needed for high customer satisfaction in low gender egalitarian workforces.

Based on this logic we predict:

Hypothesis 3: The relationship between WLS practices and customer satisfaction is moderated by gender egalitarianism in a subsidiary's country of operation, such that high gender egalitarianism strengthens the relationship between availability of WLS practices and customer satisfaction.

\section{Methods}

\section{Research setting}

- The research setting for this study is a large European multinational corporation (MNC) that has been in operation for more than 50 years, employs over 50,000 staff, and has established operations in 27 countries $^{1}$. The firm has four diverse divisions plus a shared services unit. The divisions operate in relatively mature industries. Division 1 is a manufacturing business with a large market share following a history of monopolistic conditions. It offers a limited range of products and has a strong focus on efficiency and process improvement to produce profit. 
Division 2 is a service-based business. Division 3 is a product-based business that has a heavy emphasis on new product and service development. Division 4 is a consulting business that concentrates on product offerings and expanding market opportunities to retain customers, resulting in a high level of innovation and a broad market and product line. Each division has multiple subsidiaries located in different countries. It is often the case that within one country two or more divisions will be operating separate subsidiaries.

The level of analysis for this study is that of the subsidiary, defined as value-adding entities in host countries (Birkinshaw \& Hood, 1998: 774). Drawing on Birkinshaw and Morrison's (1995: 733) typology of MNC subsidiaries, the subsidiaries within each division could be best described as "local implementers" with limited geographic scope, operating out of a single country. None of the subsidiaries had a "world mandate" with worldwide or regional responsibilities or could be classified as "centres of excellence" (Ambos \& Reitsperger, 2004). In the subject firm, across subsidiaries there are high levels of discretion and autonomy with regard to resource utilization, including the management of the local workforce.

\section{Data collection}

In this study data were collected from multiple sources which are summarized in Table I. These included surveying members of each subsidiary's TMT; data gathered from the annual external customer satisfaction survey administrated by MNC headquarters; archival company data provided by the chief operations officer (COO) and chief financial officer (CFO) and data obtained from the GLOBE project (House et al., 2002).

\section{Insert Table I about here}


Our survey targeted all members of each subsidiary's TMT, which consisted of the most senior managers of each subsidiary (e.g., general manager and deputy general managers). We obtained survey responses from TMT members in every subsidiary across each of the 27 countries in which the MNC had operations while they attended a company-sponsored leadership program offered by the authors' institution ${ }^{2}$. Of the 289 surveys distributed, 213 useable responses were returned at the conclusion of the program, giving a response rate of $74 \%$. The high response rate was attributed to the strong support for the research by senior executives of the subject firm and the continuous input of research outcomes into the education program over several years. Of the responses obtained, 16 were received from general managers in the shared services unit, which is part of the company's corporate headquarters. These 16 responses were discarded because the shared services unit does not collect satisfaction ratings from external customers. The final sample represented 97 subsidiaries from 27 countries across the four business divisions.

\section{Independent variables}

WLS practices. This variable was measured using an adapted version of Judge, Boudreau and Bretz's (1994) scale, which is provided in Appendix 1. The scale measures the availability of organizational practices to balance the demands of work and non-work responsibilities (e.g., career requirements, dual-career couples, family, leisure, health and the community). TMT members were asked to indicate whether they agreed with the items using a seven-point Likert scale where $1=$ strongly disagree and $7=$ strongly agree. The reliability for this measure was high (Cronbach $\mathrm{s} \pm=.88$ ). Given survey responses were gathered from multiple TMT members within the same subsidiary, within-group agreement is an important indicator to justify the aggregation of these responses (Chan, 1998). We calculated aggregation, $\mathrm{r}_{\mathrm{wg}}$ (James, Demaree \& Wolf, 1984) and intra-class correlation coefficients ICC(1) and ICC(2) (Bryk \& Raudenbush, 
1992) for subsidiary WLS practices. The ICC(1) score was .43 , the ICC(2) was .89 and the $r_{\mathrm{wg}}$ is .87. Based on these indices, we concluded that aggregation for WLS practices to the subsidiary level was justified.

Percentage of members of the TMT with children. In the survey, TMT members were asked if they had children (yes/no). From these demographics, the percentage of TMT members with children was calculated.

Gender egalitarianism of the country was measured at the country level using GLOBE scores (House et al., 2002). The GLOBE program focuses on culture and leadership in 61 nations. The GLOBE project differentiates between two cultural manifestations: institutional practices, reported "as is," and values, reported "as should be." In this study, we included both practices and values in the research design.

\section{Dependent variable}

Customer satisfaction. The tool used to measure customer satisfaction is known as the American Customer Satisfaction Index (ACSI) developed by Fornell, Johnson, Anderson, Cha and Bryant (1996). The ACSI measures quality of goods and services provided as experienced by the customers that consume them. The overall score has three antecedents: perceived quality, perceived value, and customer expectations. A number of scholars note that the ACSI is an effective measure for evaluating, comparing and ultimately enhancing customer satisfaction across firms, industries and nations (Anderson \& Fornell, 2000; Anderson et al., 2004; Gruca \& Rego, 2005). ${ }^{3}$ The COO of the subject firm provided the results of the ACSI of each subsidiary for the financial years ending 2008, 2009 and 2010. We used the average score for 2009 and 2010 as the dependent variable to reduce the likelihood that the results were overly impacted by any short-term fluctuations in a subsidiary's outcomes. Data from 2008 were used as a control 
variable (see below). Scores for customer satisfaction range from 1 (low customer satisfaction) to 6 (high customer satisfaction).

\section{Control variables}

Following Becker, Atinc, Breaugh, Carlson et al., (2016) recommendation we controlled for several variables that are theoretically related or have been found to be empirically related to customer satisfaction.

High-commitment human resource management (HC-HRM). Prior research has established a link between HC-HRM and firm performance (Jiang, Lepak, Hu \& Baer, 2012); with a number of studies specifically finding that HRM has effects on various customer outcomes (Jiang, Chuang \& Chiao, 2015; Hong, Liao, Hu \& Jiang, 2013). HC-HRM was measured using Snell and Dean's (1992) 32-item scale. Managers were asked questions with regard to recruitment, selection, training, performance development, evaluation, remuneration and rewards. For each HR practice, respondents indicated the extensiveness of activities by checking a sevenpoint scale, where extremes were anchored with adjectives fitting the specific question. Following the same treatment for WLS practices, we calculated the ICC(1) and ICC(2) to justify aggregation of HC-HRM scores. The ICC1 was .33 and the ICC2 was .61. While the ICC2 value was slightly below the usual level, given the small group size, aggregation is deemed acceptable (LeBreton \& Senter, 2008). The reliability of this measure is high (Cronbach $\mathrm{s} \pm=.98$ ).

Subsidiary size. This measure has been found to be related to increased resources and autonomy, with increasing size requiring greater coordination complexity (Johnston \& Menguc, 2007). Given the potential impact of firm size, we obtained the number of full-time equivalent employees in each subsidiary in 2010. This information was drawn from archival company records and provided by the CFO. A natural log transformation was applied in order to address skewness in the distribution of the variable. 
Customer satisfaction 2008. Consistent with the recommendations of prior research (Wright, Gardner, Moynihan \& Allen, 2005), we controlled for subsidiary customer satisfaction prior to the time period of our study when testing our hypotheses so that the time-lagged effect of WLS practices and customer satisfaction could be captured and reverse causality ruled out.

\section{Analysis}

Our data at the subsidiary level are nested within divisions and within countries, which means subsidiaries are classified hierarchically by their division and by their country. Therefore, we used cross-classified random multi-level modelling (Fielding \& Goldstein, 2006) to test our hypotheses. The cross-classification (division and country) is at level 2, and the subsidiary is at level 1. In this sense it is a two-level model, yet the level-2 categories are combinations of a particular division and country (see Fielding \& Goldstein, 2006).

The cross-classified multi-level model estimates the random effects of division and country in the same model. By doing this, we are able to control for different market aspects that vary across countries. This also allows us to control for the differing types of customer contact that might exist across the different divisions in the company which could influence customer satisfaction (Liao \& Subramony, 2008). The estimation of the residual components of variance reveals the extent to which variation in outcomes might be attributable to unobserved influences operating at level 2.

\section{Results}

Table II presents the means, standard deviations and zero-order Pearson correlations of all key variables and the controls. 
The results of the hypotheses tests are presented in Table III. Model 0 shows the results of the empty model. The results of the empty model show that $70 \%$ of the variance in customer satisfaction can be explained by the subsidiary, $27 \%$ can be explained by the country of the subsidiary and 3\% can be explained by the division of the subsidiary. In model 1 the controls were added. Only customer satisfaction 2008 contributes significantly to the explanation of customer satisfaction $2009 / 10(.25, p<.01)$.

\section{Insert Table III about here}

Hypothesis 1 predicts a positive relationship between WLS practices and customer satisfaction. The results are shown in model 2. After controlling for customer satisfaction 2008, HC-HRM and size of the subsidiary, the effect of WLS practices on customer satisfaction was significant $(.25, p<.01)$. This result supports Hypothesis 1 .

Hypothesis 2 predicts that the percentage of TMT members with children strengthens the effect of WLS practices on subsidiary customer satisfaction. Both percentage of TMT members with children and WLS practices were median-centered (Aiken \& West, 1991) before calculating the interaction. The result of this hypothesis is presented in Table III, model 3. The percentage of TMT members with children was not related to customer satisfaction (-.05, n.s.), however, the interaction between WLS practices and the percentage of TMT members with children was significant $(.16, p<.01)$. Using Aiken and West's (1991) procedure, the interaction is depicted in Figure 1. The figure illustrates that the relationship between WLS practices and customer satisfaction is more positive when the percentage of TMT members with children is high. Furthermore, simple slope analyses revealed that WLS practices had a positive effect on customer satisfaction performance when the percentage of TMT members with children is high 
(simple slope: $\left.{ }^{2}=.23, p<.05\right)$, while the effect of WLS practices on customer satisfaction performance was not significant when the percentage of TMT members with children is low (simple slope: ${ }^{2}=.04$, n.s.). These results support Hypothesis 2.

Hypothesis 3 predicts that the level of country gender egalitarianism strengthens the effect of WLS practices on subsidiary customer satisfaction. This hypothesis was tested for both country gender egalitarian practices and gender egalitarian values. Both gender egalitarian practices and gender egalitarian values were median-centered (Aiken \& West, 1991) before calculating the interaction with WLS practices. The results are presented in model 4 (for gender egalitarian practices) and model 5 (for gender egalitarian values). Although the main effect for gender egalitarian practices $(-.07$, n.s.) was not significant, the main effect of gender egalitarian values $(.14, p<.05)$ on customer satisfaction was significant. The WLS practices and gender egalitarian values and practices interaction terms were both significant (for both: .14, $p<.01$ ). Using the Aiken and West (1991) procedure, the interactions are depicted in Figures 2 and 3. The figures illustrate that the relationship between WLS practices and customer satisfaction is more positive when country gender egalitarianism is high. Simple slope analyses revealed that WLS practices had no effect on customer satisfaction performance when country gender egalitarianism was low (simple slope: ${ }^{2}=.09$, n.s. for practices and $.07, n . s$. for values), while the effect of WLS practices on customer satisfaction performance was significant and positive when country gender egalitarianism was high (simple slope: ${ }^{2}=.34, p<.01$ for practices and ${ }^{2}=.29, p<.01$ for values.). These results support Hypothesis 3.

\section{Discussion}

Over the last decade, demographic shifts such as increased participation of women in the workplace, dual-career couples, an aging population and changes in family composition have all placed pressure on employers to provide more flexibility for employees to balance work and non- 
work responsibilities. In response many organizations have made available WLS practices to their employees and scholars have argued that such practices should be regarded as part of the HRM literature because they are so integral to effective management of employees (McCarthy, Darcy \& Grady, 2010; Perry-Smith \& Blum, 2000).

Past research has shown that WLS practices can influence employee outcomes; however, less is known about the impact of WLS practices on organizational outcomes. The dual objective of this study was to investigate the relationship between WLS practices and customer satisfaction and the boundary conditions which might influence this relationship. Our findings suggest that WLS practices can have a positive impact of organizational customer satisfaction performance. Furthermore, drawing on contingency theory, we find that the customer satisfaction benefits of WLS practices vary across situational factors such as TMT composition and country differences. In particular, our results highlight that those subsidiaries with high numbers of TMT members with children were significantly more likely to realize customer satisfaction benefits from WLS initiatives. Another important finding of our study is that the culture of the country within which a firm operates influences the value organizations derive from WLS practices. In our study firms operating in countries with high levels of gender egalitarianism had $12 \%$ higher levels of customer satisfaction when they had high levels of WLS practices.

\section{Theoretical Implications}

\section{WLS practices - Customer satisfaction}

Social exchange theory predicts that the provision of supportive HRM practices, such as WLS practices, can motivate employees such that they invest greater effort, which subsequently enhances firm outcomes (Aryee et al., 2002). Our findings are consistent with this logic and suggest that the implementation of WLS practices may trigger a sense of reciprocity among employees, leading to greater effort to meet the needs of customers. This means that investing in 
WLS practices has the potential to be an important strategic tool for organizations seeking to enhance customer-related outcomes.

\section{Boundary condition: TMT members with children}

We theorize that TMTs with a larger proportion of members with children had a heightened awareness and understanding of the need for employees to balance work and nonwork responsibilities. Firms with strong representation of parents in the TMT may create a culture that is supportive of employees using available WLS practices, which in turn helps to generate a sense of reciprocity that encourages the discretionary behavior needed for high levels of customer satisfaction.

Prior research has noted that simply having formal WLS practices in place may be inadequate for organizations to achieve desired benefits (Allen, 2001; Thompson, Beauvais \& Lyness, 1999). Indeed, scholars have pointed to the importance of line managers in the application of WLS practices, which can potentially explain inconsistent benefits for employees (McCarthy et al., 2010). We extend this line of reasoning by illustrating the value of using an upper echelon perspective to guide theory development on the firm-level benefits associated with WLS practices. Our findings address a gap in the literature by examining the role that seniorlevel executives play in shaping the organizational benefits derived from WLS practices (McCarthy et al., 2010).

\section{Boundary condition: National culture}

The finding that cultural values influence the WLS-customer satisfaction relationship is consistent with prior work theorizing that the performance benefits of HR practices vary based on the attributes of a firm's external environment (e.g., Budhwar \& Sparrow, 2002; Schuler et al., 1993). In particular, our results highlight the importance of national culture in understanding the effectiveness of WLS practices across an international setting. While scholars have examined the 
link between national culture and the availability of WLS practices (e.g., Korabic, Lero \& Ayman, 2003; Poelmans \& Sahibzada, 2004; Raghuram, London \& Larsen, 2001), less research has examined how culture influences the relationship between WLS practices and firm-level performance outcomes, such as customer satisfaction. Thus, the results of this study extend previous research by providing greater precision about when and how norms and customs related to gender roles can influence the effective functioning of WLS practices.

The finding that gender egalitarianism moderates the impact of WLS on customer satisfaction may have implications for our understanding of how employees navigate the social exchange process with employers across countries. For example, one plausible explanation for why WLS practices did not impact customer satisfaction in low gender egalitarian countries is that employees in these countries see WLS practices as less useful or necessary. Thus, because they perceive themselves as receiving something of less value, they develop a lower sense of obligation to engage in customer-centric forms of discretionary behavior. A potentially fruitful extension of this study would thus be to examine how employees from culturally different countries value and respond to different types of WLS practices and the implications these differences might have for firm outcomes.

\section{Practical Implications}

Our findings provide evidence that organizational managers should formally consider the role of the broader organizational environment when implementing WLS practices if they are concerned with maximizing performance outcomes such as customer satisfaction. The application of a "best practice" approach, where a firm simply imitates the WLS practices used by other companies or even used in other parts of its own organization, may be misguided. For the specific outcome of customer satisfaction, maximizing the benefits associated with WLS practices requires that organizations develop an optimal portfolio of a certain type of senior manager and 
give consideration to the culture of the country within which the firm operates. Consistent with the predictions of the resource-based view (Barney, 1991), aligning implementation of WLS practices with other key internal firm attributes and external environmental factors has the potential to generate performance differences that may be difficult for other organizations to imitate. Thus, the results of this study offer organizational managers deeper insight into how they can use WLS practices to enhance the non-financial performance outcomes of their organizations. At a practical level, our finding concerning TMT parental status should provide additional motivation for organizations to ensure senior leaders appreciate the strain that work-life conflict can place on employees. In particular, senior leaders without children can be sensitized to these issues if the benefits of WLS practices are to be realized. For example, a firm's internal communications may include the sharing of cases where talent gaps have been filled or excellent employees retained by the provision of WLS practices as well as how specific WLS practices have helped employees manage non-work responsibilities.

Our results also raise questions about the generalizability of WLS practices across countries with different cultures. In low gender egalitarian countries local norms and stereotypes pertaining women's involvement in the workplace present a clear tension for MNCs that have a policy of standardizing their HR practices due to a desire to have a common culture across the firm and/or to maximize operational efficiency. MNC with headquarters based in high gender egalitarian countries are likely to derive little value by implementing WLS practices in low gender egalitarian countries. Our results show that in isolation from other considerations there are benefits in MNCs selectively implementing WLS practices across countries based on an understanding of a country's gender egalitarian practices and values.

\section{Future Research and Limitations}


There are several domains where future research might build upon this study to extend our understanding of the performance benefits associated with implementation of WLS practices. First, in this study we investigated how one aspect of a TMT's composition, TMT members with children, can influence the relationship between WLS practices and customer satisfaction. Our findings suggest that future research may benefit from using an upper echelon perspective to explore how other TMT attributes influence the impact of WLS practices on a wide variety of firm performance outcomes.

Second, a conceptual underpinning of this study is that implementation of WLS practices influences organizational performance outcomes by shaping both the attitudes and behaviors of employees. While we utilized an unmeasured social exchange-related construct to theoretically explain this relationship, we were unable to formally test this mediating mechanism with employee data. Although statistical tests find that this is less likely a concern (Lin, et al., 2016), future researchers may seek to address this limitation in their research design. This can be done by developing and testing multi-level moderated-mediation models to verify the mechanisms by which implementation of WLS practices interacts with organizational attributes to influence customer satisfaction.

Third, in our study we theorize the TMT attributes can play a role in shaping how comfortable employees are to utilize available WLS practices. However, we did not measure the work-family support climate of the units in our study. Future research could build upon our study by empirically examining this mediating mechanism.

Fourth, our focus on TMT members with children does not take into account whether the children are minors or dependents. We do not believe this to be an important factor jeopardizing the results because it is experience as a parent (whether past or present) that fosters sensitivity in 
a leader to the challenges of balancing work and non-work responsibilities. This awareness is cultivated during child rearing years but not limited to this life stage.

Fifth, our data were collected from a single MNC. Thus, it would be of value for future research to examine whether our patterns of results generalize to other types of MNCs, different types of subsidiaries and other industries. It would be of particular interest to see whether other attributes such as an MNC's organizational structure play a role in shaping the benefits firms derive from WLS practices.

These limitations notwithstanding, our study makes an important contribution to the HRM literature by providing new theoretical and empirical insights into the relationship between the implementation of WLS practices and organizational customer satisfaction performance. Examining this relationship across 27 countries provides a unique global perspective on the role that WLS practices can play in organizations. By formally considering the role of internal firm attributes and external environmental factors, the study provides specific guidance on when WLS can be of the greatest value.

\section{Acknowledgement}

The first author would like the thank staff at D'Amore-McKim School of Business at Northeastern University for feedback and assistance in developing the manuscript during a visit.

Julie A. Cogin is the Director of the Australian Graduate School of Management (AGSM) and Deputy Dean UNSW Business School. Her research interests surround the HRM-performance relationship. This includes understanding how components of an HRM strategy can be configured to realize superior organizational financial and non-financial outcomes (in both profit and not-for-profit sectors) as well as the impediments to HRM professionals operating as true strategic partners.

Karin Sanders $\mathrm{PhD}$ (University of Groningen, the Netherlands), is Professor of Human Resource Management and Organizational Behavior at the UNSW Australia Business School, and Head of School of Management. Her research focuses on the HRM process approach -in particular, the impact of employees' perceptions and understanding (attributions) of HRM on their attitudes and behaviors. Her research has been published in such scholarly outlets as the Journal of Vocational Behavior, Organizational Studies, Organizational Science, Human Resource Management, international Journal of Human Resource Management, Human Resource 
Management Journal, British Journal of Management and Academy of Management Learning \& Education.

Ian O. Williamson is Associate Dean, International Relations at the Melbourne Business School (Australia). He also serves as Director of the Asia Pacific Social Impact Centre, where his focus is on developing effective cross-sector partnerships to address key economic and social issues. His research examines the effective "talent pipelines" have on organizational and community outcomes. In particular, he examines how human and social capital influences firm operational and financial outcomes, talent management in the context of new ventures and growth-oriented firms, the role of human resource practices in driving firm innovation and the impact of social issues on firm outcomes.
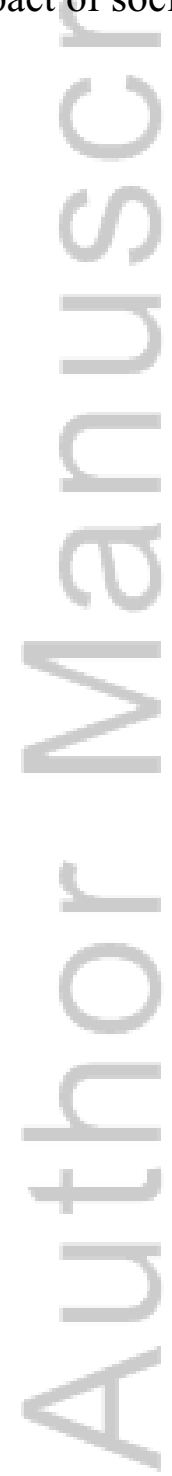


\section{References}

Aiken, L. S. \& West, S. G. (1991). Multiple regression: Testing and interpreting interactions. Newbury Park: Sage.

Allen, T.D. (2001). Family-supportive work environments: The role of organizational perceptions. Journal of Vocational Behavior. 58, 414-435.

Allen, T.D., Herst, D.E.L., Bruck, C.S. \& Sutton, M. (2000). Consequences associated with work-to-family conflict: A review and agenda for future research. Journal of Occupational Health Psychology, 5, 278-308.

Ambos, B. \& Reitsperger, W.D. (2004). Offshore centers of excellence: Social control and success. Management International Review, 44(2), 51-63.

Anderson, E.W. \& Fornell, C.C. (2000). The customer satisfaction index as a leading indicator, in Handbook of Services Marketing and Management, Swartz, T.R. \& Iacobucci, D. eds. Thousand Oaks: Sage

Anderson, E.W., Fornell, C.C. \& Mazvancheryl, S.K. (2004). Customer satisfaction and shareholder value. Journal of Marketing, 68(4), 172-185.

Arthur, M. M. (2003). Share price reactions to work-family human resource decisions: An institutional perspective. Academy of Management Journal, 46(4), 97-505.

Arthur, M. M. \& Cook, A. (2003).The relationship between work-family human resource practices and firm profitability: A multi-theoretical perspective. Research in Personnel and Human Resources Management Review, 22(2), 19-252.

Arthur, M. M. \& Cook, A. (2004). Taking stock of work-family initiatives: How announcements of 'family-friendly' human resource decisions affect shareholder value. Industrial and Labor Relations Review, 57, 599- 613.

Aryee, S., Budhwar, P.S. \& Chen, Z.X. (2002). Trust as a mediator of the relationship between organizational justice and work outcomes: Test of a social exchange model. Journal of Organizational Behavior, 23(3), 267-285.

Aryee, S., Srinivas, E. \& Tan, H. (2005). Rhythms of life: Antecedents and outcomes of work family balance in employed parents. Journal of Applied Psychology, 90, 132-146.

Bainbridge, H. T. J., Sanders, K., Cogin, J. A. \& Lin, C. H. (2016). The pervasiveness and trajectory of methodological choices: A 20-year review of human resource management research. Human Resource Management, doi:10.1002/hrm.21807.

Barker, V. L., III. \& Mueller, G.C. (2002). CEO characteristics and firm R\&D spending. Management Science, 48(6), 782-801. 
Barney, J. B. (1991). Firm resources and sustained competitive advantage. Journal of Management, 17, 99-120.

Batt, R. 2002. Managing customer services: Human resource practices, quit rates, and sales growth. Academy of Management Journal, 45(3), 587-597.

Batt, R., Holman, D. \& Holtgrewe, U. (2009). The globalization of service work: Comparative institutional perspectives on call centers. Industrial and Labor Relations Review, 62(4), 453-488.

Becker, T. E., Atinc, G., Breaugh, J. A., Carlson, K. D., Edwards, J. R. \& Spector, P. E. (2016). Statistical control in correlational studies: Ten essential recommendations for organizational researchers. Journal of Organizational Behavior, 37(2), 157-167.

Beltrán-Martín, I., Roca-Puig, V., Escrig-Tena, A. \& Carlos, J. (2008). Performance work systems and performance: Human resource flexibility as a mediating variable between high performance work systems and performance. Journal of Management, 34(5), 1009-1044.

Birkinshaw, J. \& Hood, N. (1998). Multinational subsidiary evolution: Capability and charter in foreign-owned subsidiary companies. Academy of Management Review, 23(4), 773-795.

Birkinshaw, J.M. \& Morrison, A.J. (1995). Configurations of strategy and structure in subsidiaries of multinational corporations. Journal of International Business Studies, 26 (4), 729-753.

Boxall, P. \& Purcell, J. (2011). Strategy and Human Resource Management, 3rd ed. London: Palgrave Macmillan.

Bryk, A.S. \& Raudenbush, S.W. (1992). Hierarchical linear models: Applications and data analysis methods. Newbury Park: Sage.

Budhwar, P.S. \& Sparrow, P.R. (2002). An integrative framework for understanding crossnational human resource management practices. Human Resource Management Review, $12,377-403$.

Butts, M.M., Casper, W.J. \& Yang, T.S. (2012). How important are work-family support programs? A meta-analysis of their effects on work related outcomes. Journal of Applied Psychology, 98(1), 1-25.

Chadwick, C., Super, J.F. \& Kwon, K. (2015). Resource orchestration in practice: CEO emphasis on SHRM, commitment-based HR systems and firm performance. Strategic Management Journal, 36, 360-376.

Chan, D. (1998). Functional relations among constructs in the same content domain at different levels of analysis: a typology of composition models. Journal of Applied Psychology, 83(2), 234-246.

This article is protected by copyright. All rights reserved. 
Colakoglu, S., Allen, M., Miah, K. \& Bird, A. (2016) High investment HR values and firm performance among local firms and U.S. MNCs' subsidiaries in South Asia: A comparative study. The International Journal of Human Resource Management, 27:13, 1426-1447.

Cotter, D., Hermsen, J.M. \& Vanneman, R. (2011). The end of the gender revolution? Gender role attitudes from 1977 to 2008. American Journal of Society, 117(1), 259-289.

Cropanzano, R. \& Mitchell, M.S. (2005). Social exchange theory: An interdisciplinary review. Journal of Management, 31, $874-900$.

Eisenberger, R., Stinglhamber, F., Vandenberghe, C., Sucharski, I.L. \& Rhoades, L. (2002). Perceived supervisor support: Contributions to perceived organizational support and employee retention. Journal of Applied Psychology, 87(3), 565-573.

Fielding, A. \& Goldstein, H. (2006). Cross-classified and multi membership structures in multilevel models: An introduction and review, research report RR791. Birmingham, UK: University of Birmingham.

Finkelstein, S. \& Hambrick, D.C. (1996). Strategic leadership: Top executives and their effects on organizations. New York: West Publishing Company.

Fornell, C., Johnson, M.D., Anderson, E.W, Cha, J. \& Bryant, B. (1996). The American customer satisfaction index: description, findings and implications. Journal of Marketing, 60(10), 718.

Fulmer, I.S. \& Ployhart, R. (2014). “Our most important asset”: A multidisciplinary/multilevel review of human capital valuation for research and practice. Journal of Management, 40(1), 157- 188 .

Greenhaus, J.H., Ziegert, J.C. \& Allen, T.D. (2012). When family-supportive supervision matters: Relations between multiple sources of support and work-family balance. Journal of Vocational Behavior, 80(2), 266-275.

Grover, S.L. \& Crooker, K. J. (1995). Who appreciates family-responsive human resource policies: The impact of family friendly policies on organizational attachment of parents and non-parents. Personnel Psychology, 48, 271-288.

Gruca, T.S. \& Rego, L.L. (2005). Customer satisfaction, cash flow, and shareholder value. Journal of Marketing, 69,115-130.

Guo, L., Xiao, J. J., \& Tang, C. (2009). Understanding the psychological process underlying customer satisfaction and retention in a relational service. Journal of Business Research, 62, 1152-1159.

Gustafsson, A., Johnson, M.D. \& Roos, I. (2005). The effects of customer satisfaction, relationship commitment dimensions, and triggers on customer retention. Journal of Marketing, 69(4), 210-218.

This article is protected by copyright. All rights reserved. 
Hammer, L.B., Kossek, E., Bodner, T., Crain, T. (2013). Measurement development and validation of the family supportive supervisor behavior short-form (FSSB-SF). Journal of Occupational Health Psychology, 18(3), 285-296.

Hambrick, D. C. (1989). Guest editor's introduction: Putting top managers back in the strategy picture. Strategic Management Journal, 10, 5-15.

Hambrick, D. C. \& Mason, P. (1984). Upper echelons: The organization as a reflection of its top managers. Academy of Management Review, 9: 193-206.

Higgins, M. C. \& Gulati, R. (2006). Stacking the deck: the effects of top management backgrounds on investor decisions. Strategic Management Journal, 27(1), 1-25.

Hofstede, G. (2001). Culture's Consequences: Comparing values, behaviors, institutions and organizations across nations, 2nd Edition. Thousand Oaks: Sage.

Hong, Y., Liao, H., Hu, J. \& Jiang, K. (2013). Missing link in the service profit chain: A metaanalytic review of the antecedents, consequences, and moderators of service climate. Journal of Applied Psychology, 98 (2), 237 - 267.

House, R., Javidan, M., Hanges, P. \& Dorfman, P. (2002). Understanding cultures and implicit leadership theories across the globe: an introduction to project GLOBE. Journal of World Business, 37, 3-10.

James, L. R., Demaree, R. G. \& Wolf, G. (1984). Estimating within-group interrater reliability with and without responses bias. Journal of Applied Psychology, 69, 85-98.

Jiang, K., Lepak, D. P., Hu, J. \& Baer, J. C. (2012). How does human resource management influence organizational outcomes? A meta-analytic investigation of mediating mechanisms. Academy of Management Journal, 55, 1264-1294.

Jiang, K., Chuang, C.H. \& Chiao, Y.C. (2015). Developing collective customer knowledge and service climate: The interaction between service-oriented high-performance work systems and service leadership. Journal of Applied Psychology, 100(4), 1089 - 1106.

Johnson, M. D. \& Fornell, C. (1991). A framework for comparing customer satisfaction across individuals and product categories. Journal of Economic Psychology, 12 (2), 267-86.

Johnston, S. \& Menguc, B. (2007). Subsidiary size and the level of subsidiary autonomy in multinational corporations: a quadratic model investigation of Australian subsidiaries. Journal of International Business Studies, 38(5), 787-801.

Judge, T. A., Boudreau, J. W. \& Bretz, R. D., Jr. (1994). Job and life attitudes of male executives. Journal of Applied Psychology, 79, 767-782. 
Kailasapathy, P., Kraimer, M.L. \& Metz, I. (2014). The interactive effects of leader-member exchange, gender and spouse's gender role orientation on work interference with family conflict. The International Journal of Human Resource Management, 25(19), 2681-2701.

Kelly, E.L., Kossek, E.E., Hammer, L.B., Durham, M., Bray, J., Chermack, K., Murphy, L.A. \& Kaskubar, D. (2008). Getting there from here: Research on the effects of work-family initiatives on work-family conflict and business outcomes. Academy of Management Annuls, 305-349.

Kinnunen, U. \& Mauno, S. (1998). Antecedents and outcomes of work-family conflict among employed women and men in Finland. Human Relations, 51, $157-177$.

Konrad, A. M. \& Mangel, R . (2000). The impact of work-life programs on firm productivity. Strategic Management Journal, 21, 1225-1237.

Korabik, K., Lero, D.S. \& Ayman, R. (2003). A multi-level approach to cross cultural workfamily research: a micro and macro perspective. International Journal of Cross Cultural Management, 3, 289-303.

Kossek, E.E., Pichler, S., Bodner, T. \& Hammer, L.B. (2011). Workplace social support and work-family conflict: A meta-analysis clarifying the influence of general and work-family specific supervisor and organizational support. Personnel Psychology, 64(2), 289-313.

Kumar, V. \& Peterson, J.A. (2005). Using a customer-level marketing strategy to enhance firm performance: a review of theoretical and empirical evidence. Journal of the Academy of Marketing Science, 33(4), 504-519.

Lambert, S.J. (2000). Added benefits: the link between work-life benefits and organizational citizenship behavior. Academy Management Journal, 43(5), 801-815.

LeBreton, J. M. \& Senter, J. L. (2008). Answers to 20 questions about interrater reliability and interrater agreement. Organizational Research Methods, 11(4), 815-852.

Li, X., Qin, X., Jiang, K., Zhang, S. \& Gao, F.Y. (2015). Human resource practices and firm performance in china: the moderating roles of regional human capital quality and firm innovation strategy. Management and Organizational Review, 11 (2), 237-261.

Liao, H., \& Subramony, M. (2008). Employee customer orientation in manufacturing organizations: Joint influences of customer proximity and senior leadership team. Journal of Applied Psychology, 93, 317-328.

Lin, C.H.V., Sanders, K., Sun, J.J.M., Shipton, H. \& Mooi, E.A. (2016). From customer-oriented strategy to organizational financial performance: the role of human resource management and customer-linking capability. British Journal of Management, 27, 21-27. 
Lyness, K.S. \& Judiesch, M.K. (2014). Gender egalitarianism and work-life balance for managers: Multisource perspectives in 36 countries. Applied Psychology: An International Review, 63 (1), 96-129.

McCarthy, A., Darcy, C. \& Grady, G. (2010). Work-life balance policy and practice: Understanding line manager attitusdes and behaviors. Human Resource Management Review, 20, 158-167.

Morrison, E.W. (1996). Organisational citizenship behavior as critical link between HRM practices and service quality. Human Resource Management, 35 (4), 493-512.

Nagar, V. \& Rajan, M.V. (2005). Measuring customer relationships: The case of the retail banking industry. Management Science, 51(6), 904-919.

Ngo, H., Foley, S. \& Loi, R. (2009). Achieving work-family balance: Theoretical and empirical advancements. Journal of Organizational Behavior, 30(5), 665-680.

Nielsen, B. \& Nielsen, S. (2011). The role of top management team international orientation in international strategic decision-making: The choice of foreign entry mode. Journal of World Business, 46, 185-193.

Nishii, L.H., Lepak, D.P. \& Schneider, B. (2008). Employee attribution of the "why" of HR practices: their effects on employee attitudes and behaviors and customer satisfaction. Personnel Psychology, 61, 503-545.

O'Connell, V. \& O'Sullivan, D. (2013). On the use of non-financial measures in performance management: Evidence from CEO compensation schemes. Strategic Management Journal, $35(6), 826-844$.

Ollier-Malaterre, A., Valcour, M., Dulk, L.D. \& Kossek, E.E. (2013). Theorizing national context to develop comparative work-life research: A review and research agenda. European Management Journal, 31(5), 433-447.

Perry-Smith, J. E. \& Blum, T.C. (2000).Work-family human resource bundles and perceived organizational performance. Academy of Management Journal, 43, 1107-1117.

Peterson, M.F., Arregle, J.L. \& Martin, X. (2012). Multilevel models in international business research. Journal of International Business Studies, 43, 451-457.

Piszczek, M.M. \& Berg, P. (2014). Expanding the boundaries of boundary theory: Regulative institutions and work-family role management. Human Relations, 67(12) 1491-1512.

Poelmans, S. \& Sahibzada, K. (2004). A multi-level model for studying the context and impact of work-family policies and culture in organizations. Human Resource Management Review, $14,409-431$. 
Powell, G. N., Francesco, A.M. \& Ling, Y. (2009). Toward culture-sensitive theories of the work-life interface. Journal of Organizational Behaviour, 30(4), 597-616.

Rabl, T., Jayasinghe, M., Gerhart, B. \& Kuhlmann, T. M. 2014. A meta-analysis of country differences in the high-performance work system-business performance relationship: The roles of national culture and managerial discretion. Journal of Applied Psychology, 99(6), 1011-42.

Raghuram, S., London, M. \& Larsen, H.H. (2001). Flexible employment practices in Europe: Country versus culture. International Journal of Human Resource Management, 12, 738753.

Rucci, A.J., Kirn, S.P. \& Quinn, R.T. (1998). The employee-customer-profit chain at Sears. Harvard Business Review, 76 (1), 82-97.

Ruppanner, L. \& Huffman, M. L. (2014). Blurred Boundaries: Gender and Work-Family Interference in Cross-National Context. Work and Occupations, 41, 210-236.

Schneider, B., White, S. \& Paul, M. C. (1998). Linking service climate and customer perceptions of service quality: Test of a causal model. Journal of Applied Psychology, 83(2), 150-163.

Schuler, R.S., Dowling, P.J. \& De Cieri, H.D. (1993). An integrative framework of strategic international human resource management. Journal of Management, 19, 419-459.

Snell, S. \& Dean, J.W., Jr. (1992). Integrated manufacturing and human resource management: A human capital perspective. Academy of Management Journal, 35, 467-504.

Somaya, D., Williamson, I.O. \& Zhang, A. (2007). Combining patent law expertise with R\&D for patenting performance. Organization Science, 18, 922-937.

Stavrou, E. \& Kassinis, G. (2013). Non-standard work arrangements and national context. European Management Journal, 31(5), 433-536.

Stavrou, E.T., Casper, W.J. \& Ierodiakonou, C. (2015). Support for part-time work as a channel to female employment: the moderating effects of national gender empowerment and labour market conditions. The International Journal of Human Resource Management, 26(6), 688706.

Thompson, C. A., Beauvais, L. L. \& Lyness, K. S. (1999). When work-family benefits are not enough: The influence of work-family culture on benefit utilization, organizational attachment, and work-family conflict. Journal of Vocational Behavior, 54, 392-415.

Valcour, M., Ollier-Malaterre, A., Matz-Costa, C., Pitt-Catsouphes, M. \& Brown, M. (2011). Influences on employee perceptions of organizational work-life support: Signals and resources. Journal of Vocational Behavior, 79, 588-595.

Wayne, J.H., Casper, W.J., Matthews, R.A., Allen, T.D. (2013). Family-supportive organization 
perceptions and organizational commitment: The mediating role of work-family conflict and enrichment and partner attitudes. Journal of Applied Psychology, 98(4), 606-622.

World Trade Organization (2013). International trade statistics, World Trade Organization, available at https://www.wto.org/english/res_e/statis_e/its2013_e/its2013_e.pdf.

Wright, P. M., Gardner, T.M., Moynihan, L.M. \& Allen, M.R. (2005). The relationship between HR practices and firm performance: Examining causal order. Personnel Psychology, 58(2), 409-46.

Wright, P.W. \& Snell, S.A. (1998). Toward a unifying framework for exploring fit and flexibility in strategic human resource management. Academy of Management Review, 23(4), 756772.

Wood, S.J. \& de Menezes, L.M. (2010). Family-friendly management, organizational performance and social legitimacy. International Journal of Human Resource Management, 21(10), 1575-1597.

Yang, N., Chen, C. C., Choi, J. \& Zou, Y. (2000). Sources of work-family conflict: A Sino-U.S. comparison of the effects of work and family demands. Academy of Management Journal, 43(1), 113-123.

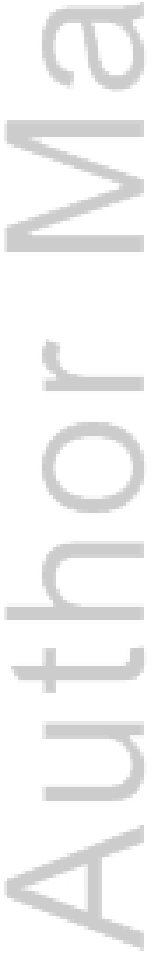

This article is protected by copyright. All rights reserved. 
Table I. Scales and variables used in our study and the source from which they were collected.

\begin{tabular}{ll}
\hline Variables & Collected from
\end{tabular}

\section{Dependent variable}

Customer satisfaction 2009/2010

\section{Independent variables}

Work-life support (WLS) practices

Percentage TMT members with children

Gender egalitarian country (GLOBE)

\section{Controls}

Customer satisfaction 2008

Subsidiary size

HC-HRM

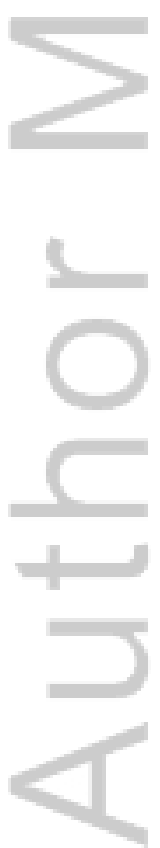

Archival company data

Survey of Subsidiary General Managers

Survey of Subsidiary General Managers

House et. al. (2002)

Archival company data

Archival company data

Survey of Subsidiary General Managers

This article is protected by copyright. All rights reserved. 
Table II. Descriptive Statistics and Correlations $(n=97)$

\begin{tabular}{|c|c|c|c|c|c|c|c|c|c|}
\hline Variable & Mean & SD & 1. & 2. & 3. & 4. & 5. & 6. & 7. \\
\hline 1. Customer satisfaction $09 / 10$ & 3.16 & 1.25 & & & & & & & \\
\hline 2. WLS practices & 4.97 & .88 & $27^{* *}$ & & & & & & \\
\hline $\begin{array}{l}\text { 3. Percentage TMT members with } \\
\text { children }\end{array}$ & .88 & .26 & .02 & $.17 *$ & & & & & \\
\hline 4. Gender egalitarian country practices & 2.17 & .32 & .01 & .14 & -.07 & & & & \\
\hline 5. Gender egalitarian country values & 1.00 & .53 & $.23 *$ & .05 & .08 & $.61 * *$ & & & \\
\hline \multicolumn{10}{|l|}{ Controls } \\
\hline 6. Customer satisfaction 08 & 3.30 & 1.64 & $.40 * *$ & .09 & -.06 & .01 & -.13 & & \\
\hline 7. Subsidiary size & 54925 & 21579 & -.17 & -.11 & -.12 & .04 & .10 & -.01 & \\
\hline 8. HC-HRM & 3.37 & 1.45 & $.34 * *$ & .16 & -.09 & -.06 & -.07 & $.47 * *$ & .12 \\
\hline
\end{tabular}

Note: $* *=p<.01 ; *=p<.05$ 
Table III. Results of Customer Satisfaction as the Dependent Variable in Cross Classified Hierarchical Regression Comparison

\begin{tabular}{|c|c|c|c|c|c|c|}
\hline 3 & Model 0 & Model 1 & Model 2 & Model 3 & Model 4 & Model 5 \\
\hline \multicolumn{7}{|l|}{ Controls } \\
\hline Customer satisfaction 08 & & $.25 * *$ & $.25 * *$ & $.25 * *$ & $.26 * *$ & $.23^{*}$ \\
\hline HC-HRM & & .09 & .09 & .09 & .07 & .10 \\
\hline Size & & -.06 & -.06 & -.05 & -.05 & -.07 \\
\hline \multicolumn{7}{|l|}{ Main effects } \\
\hline WLS practices $(\mathrm{H} 1)$ & & & $.25 * *$ & $.23 * *$ & $.24 * *$ & $.27 * *$ \\
\hline Percentage TMT with children & & & & -.05 & & \\
\hline Gender egalitarian practices & & & & & -.07 & \\
\hline Gender egalitarian values & & & & & & $.14^{*}$ \\
\hline \multicolumn{7}{|l|}{ Two way interactions } \\
\hline WLS * percentage TMT with children (H2) & & & & $.16 * *$ & & \\
\hline WLS * gender egalitarian practices $(\mathrm{H} 3)$ & & & & & $.14 * *$ & \\
\hline WLS * gender egalitarian values $(\mathrm{H} 3)$ & & & & & & $.14 * *$ \\
\hline \multicolumn{7}{|l|}{ Random effects } \\
\hline Variance at the unit level & $.72 * *$ & $.70 * *$ & $.64 * *$ & $.60 *$ & $.61^{*}$ & $.60 *$ \\
\hline Country & $.27 *$ & $.13 *$ & .10 & .10 & .09 & .07 \\
\hline Division & $.03 *$ & .03 & .02 & .02 & .01 & .01 \\
\hline Model fit & 291.92 & 277.05 & 273.32 & 265.62 & 260.21 & 257.48 \\
\hline Def. model fit & & $14.87 * *$ & $3.73 * *$ & $7.70 * *$ & $13.11^{*}$ & $15.84^{* *}$ \\
\hline
\end{tabular}


Figure 1. Customer Satisfaction as a Function of Work-Life Support (WLS) Practices and Percentage TMT with Children (H2).

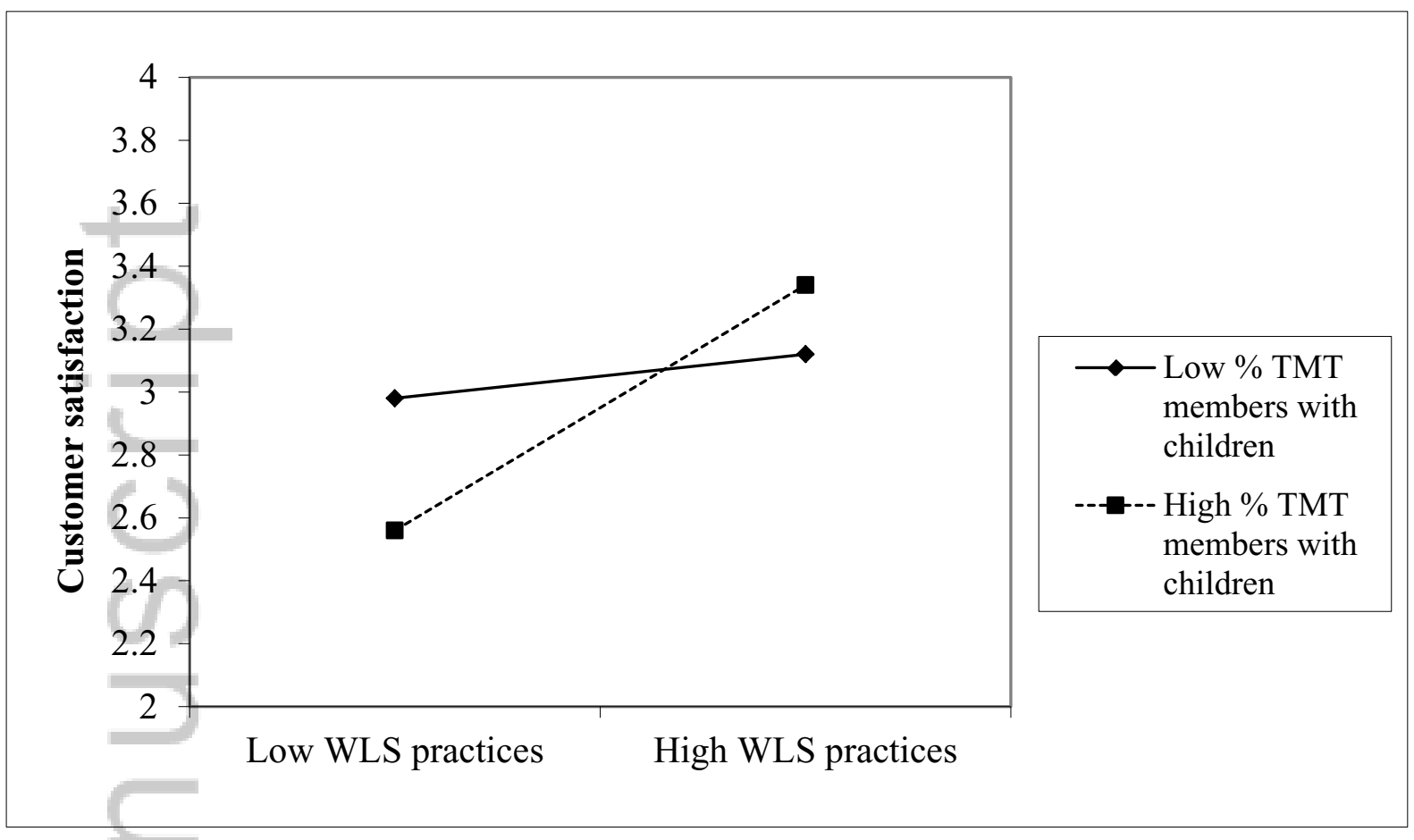

This article is protected by copyright. All rights reserved. 
Figure 2. Customer Satisfaction as a Function of Work-Life Support (WLS) Practices and Gender Egalitarian Practices

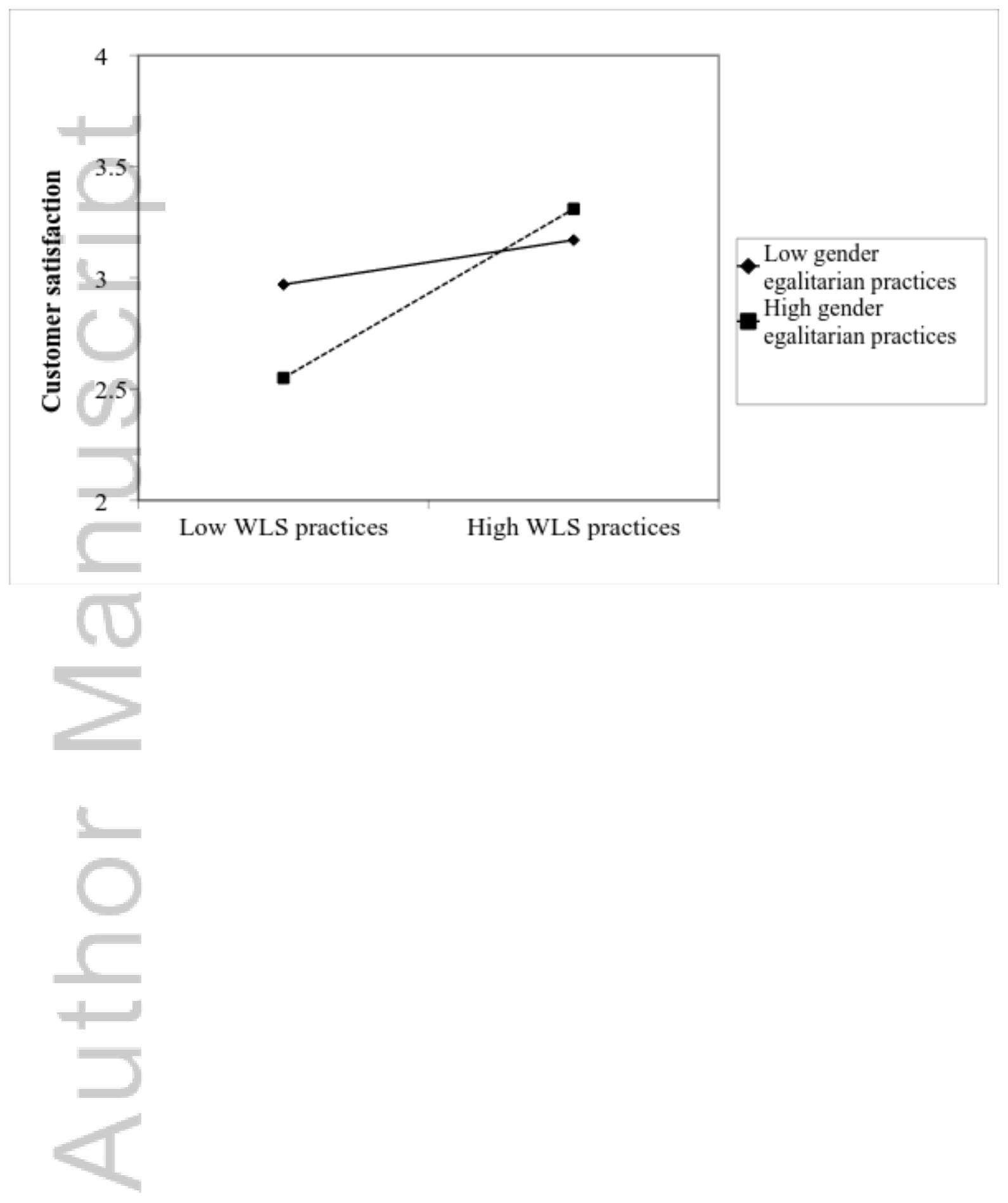

This article is protected by copyright. All rights reserved. 
Figure 3. Customer Satisfaction as a Function of Work-Life Support (WLS) Practices and Gender Egalitarian Values

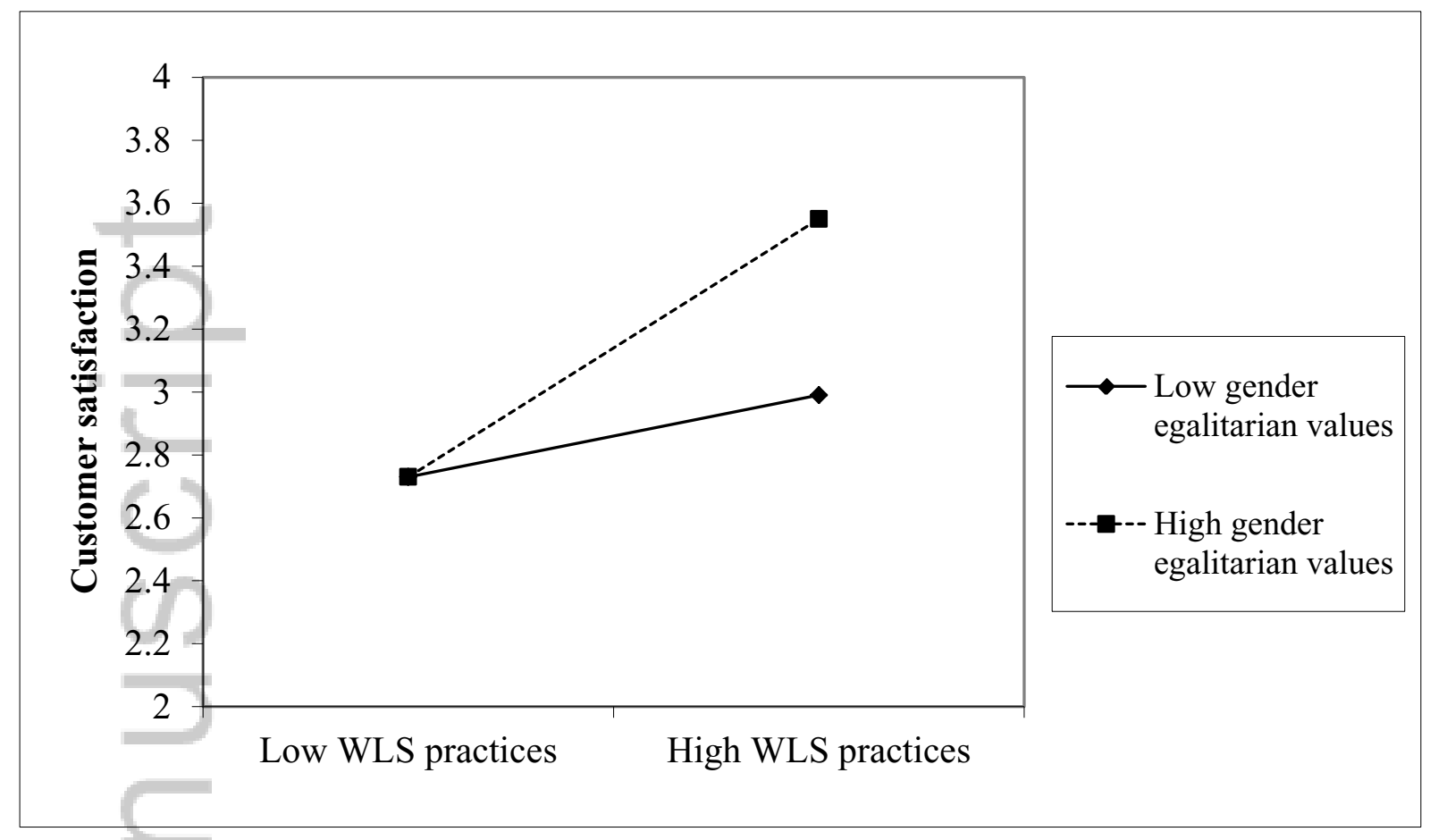

This article is protected by copyright. All rights reserved. 


\section{APPENDIX ONE}

Work-life support scale (Judge et al, 1994)

- My organization provides programs to assist balancing the demands of dual career couples

- My organization provides programs to assist in balancing the demands of families with children and/or elderly family members

- My organization stresses the importance of family, leisure, and health

- My organization provides opportunities for employees to use flexible work practices, part-time or temporary assignments

- My organization supports employee involvement in the community

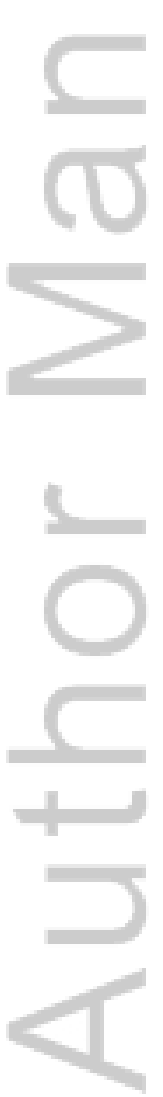

This article is protected by copyright. All rights reserved. 


\section{Notes}

\footnotetext{
${ }^{1}$ This includes Australia, Brazil, Canada, China, Denmark, Egypt, Germany, Hong Kong, India, Indonesia, Italy, Japan, Malaysia, New Zealand, Russia, Singapore, South Africa, Taiwan, Turkey, United Kingdom and United States of America plus six small pacific island countries pooled together.

${ }^{2}$ The study formed part of a larger project with the objective given on an information sheet as "This study seeks to develop a better understanding of the role of human resource management in creating and sustaining organizational performance and competitive advantage."
}

${ }^{3} \mathrm{~A}$ one-point increase in an annual ACSI score for a typical company is equal to an increase of $11.4 \%$ of return on investment, an increase of $\$ 654$ million in market value of equity above and beyond the accounting book values of assets and liabilities, an increase of $\$ 55$ million per year in net operating cash flow; and a reduction of variance in future cash flows of more than 4\% (Anderson \& Fornell, 2000; Anderson et al., 2004; Gruca \& Rego, 2005).

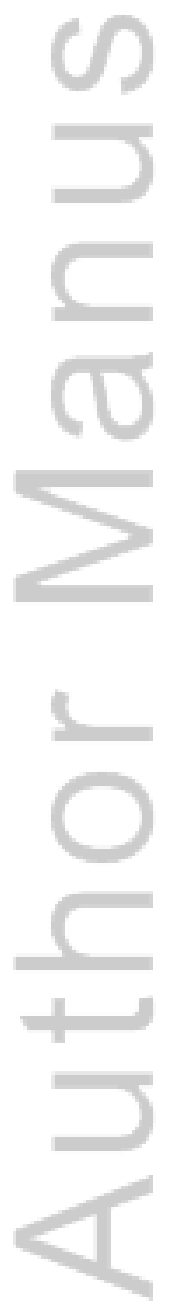




\section{University Library}

\section{- M M I N E R VA A gateway to Melbourne's research publications}

Minerva Access is the Institutional Repository of The University of Melbourne

Author/s:

Cogin, J;Williamson, I;Sanders, K

Title:

Work-Life Support Practices and Customer Satisfaction

Date:

2018-02-01

Citation:

Cogin, J., Williamson, I. \& Sanders, K. (2018). Work-Life Support Practices and Customer Satisfaction. Human Resource Management, 57 (1), pp.279-291. https://doi.org/10.1002/ hrm.21833.

Persistent Link:

http://hdl.handle.net/11343/293376 